Document downloaded from:

http://hdl.handle.net/10251/136497

This paper must be cited as:

Reyes, M.; Tinaut, F.; Giménez, B.; Pastor, JV. (2018). Effect of hydrogen addition on the $\mathrm{OH}^{*}$ and $\mathrm{CH}^{*}$ chemiluminescence emissions of premixed combustion of methane-air mixtures. International Journal of Hydrogen Energy. 43(42):19778-19791. https://doi.org/10.1016/j.ijhydene.2018.09.005

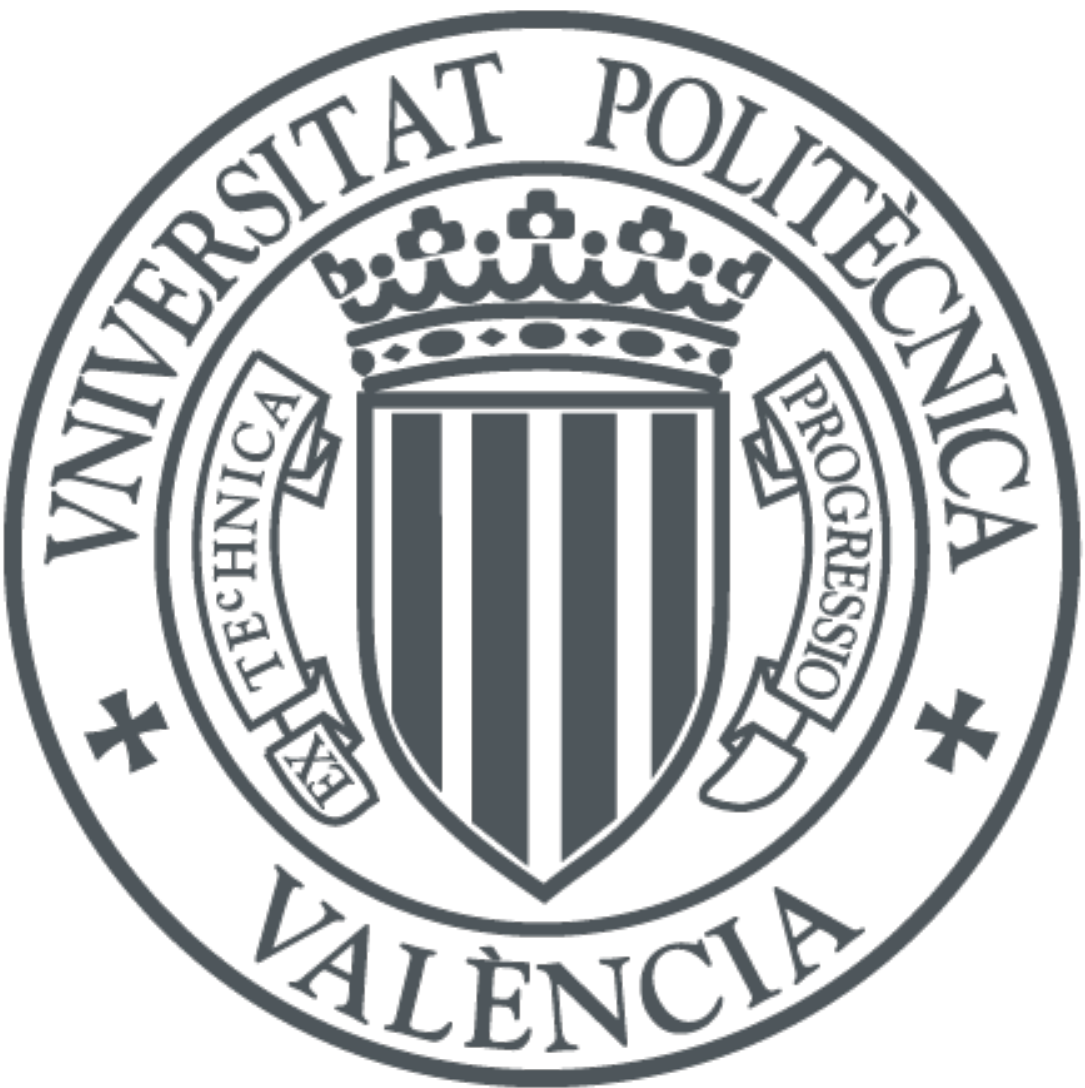

The final publication is available at

https://doi.org/10.1016/j.jijhdene.2018.09.005

Copyright Elsevier

Additional Information 


\title{
EFFECT OF HYDROGEN ADDITION ON THE OH* AND CH* CHEMILUMINESCENCE EMISSIONS OF PREMIXED COMBUSTION OF METHANE-AIR MIXTURES
}

\author{
M. Reyes ${ }^{* 1}$, F.V. Tinaut ${ }^{1}$, B. Giménez ${ }^{1}$, José V. Pastor ${ }^{2}$ \\ (1) Department of Energy and Fluid Mechanics Engineering. University of Valladolid. \\ Paseo del Cauce s/n, E-47011, Valladolid, Spain \\ (2) CMT - Motores Térmicos. Universitat Politècnica de València. Camino de Vera s/n, \\ 46022 Valencia, Spain \\ * miriam.reyes@eii.uva.es
}

\begin{abstract}
\end{abstract}
Chemiluminescence emissions measurements of $\mathrm{OH}^{*}$ and $\mathrm{CH}^{*}$ are used to characterize the combustion of blends of methane and hydrogen in air in a constant volume combustion bomb, with two sets of initial conditions. The combined results of combustion development cover from 0.1 to $2.5 \mathrm{MPa}$. Burning velocity, heat release and unburned/burned gas temperatures are obtained from the pressure by using a two-zone thermodynamic combustion diagnostic model. Intensity of $\mathrm{OH}^{*}$ and $\mathrm{CH}^{*}$ increases with the initial temperature and the percentage of hydrogen, in parallel with the usual increase in burning velocity. The timings of the peaks of $\mathrm{OH}^{*}$ and $\mathrm{CH}^{*}$ chemiluminescence emissions are found to correlate respectively with the maximum rate of heat release and flame temperature. These results show that both 
chemiluminescence signals can be used to monitorize the burning process in combustion devices operating in the pressure range studied.

Keywords: Combustion characterization, hydrogen, methane, chemiluminescence emissions, combustion bomb. 


\section{Introduction}

Due to the energy demand and concern of environmental protection, much attention is paid to the use of alternative and non-conventional fuels. Methane and hydrogen have been chosen for this study because methane is the main component of the natural gas (NG), which is considered to be a possible alternative fuel due to its properties and high octane number [1] and its combustion causes less pollutant emissions than conventional fuels [2]. However, methane has a slow laminar burning velocity, compared to other liquid fuels. Laminar burning velocity is an important property of the combustion process because fuels with high burning velocities can improve engine combustion [3]. To increase the burning velocity, it is possible to blend methane with hydrogen [4], which is an attractive fuel since it can be produced by a variety of methods and can be used to generate energy in different devices (such as Reciprocating ICE, gas turbines and fuel cells).

Burning velocities of methane-hydrogen mixtures varying from 0 to $100 \%$ in hydrogen content have been obtained and studied at different conditions of temperature and pressure by several groups for years. Huang et al. [5] studied the flame characteristics of NG-hydrogen mixtures at standard temperature and pressure, showing that laminar burning velocities increase substantially with the increment of the percentage of hydrogen in the blend. Hu et al. [6] developed an experimental and numerical study of lean mixtures of NG-hydrogen at elevated temperatures and pressures over a wide range of hydrogen percentages in the mixture, showing an increment in the un-stretched laminar burning velocity with the hydrogen content. Reyes et al. [7] characterized mixtures of natural gas and hydrogen in a single-cylinder spark ignition engine by means of a zero dimensional thermodynamic model. In the 
work developed by Tinaut et al. [8] different mixtures of NG and hydrogen were used as fuels to analyze the effect of the addition of hydrogen on the $\mathrm{CO}$ and $\mathrm{NO}$ emissions, the optimal ignition timing and performance of an ICE.

For the study of combustion of these and other types of hydrocarbon fuels, the analysis of chemiluminescence emissions is a powerful tool. Multiple research works have confirmed that chemiluminescence emitted by excited chemical radicals in flames can be used as a diagnostic combustion tool [9-11], such as in internal combustion engines (ICE), combustion bombs, burners, turbines and other facilities.

This work is focused on the interpretation of $\mathrm{OH}^{*}$ and $\mathrm{CH}^{*}$ chemiluminescence data obtained in combustions of methane/hydrogen and air, because they have been widely employed as a flame marker [12] to study the combustion process by spectral combustion diagnostics. Chemiluminescence emissions can be defined as the natural visible and near-spontaneous emission of hydrocarbon flames caused by excited molecules when they decay back to equilibrium energy levels by emitting a photon. The molecules responsible for the chemiluminescence emissions for different combustion regimes can give information about the nature of the combustion reactions and the fuel/air mixture [13]. Some authors use chemiluminescence emissions to study the combustion process by spectral combustion diagnostics [14-21]. Ballester et al. [21] monitorize $\mathrm{CH}^{*}, \mathrm{OH}^{*}$ and $\mathrm{C}_{2} *$ emissions in premixed flames (at near atmospheric pressures) of natural gas/hydrogen as a function of the fuel/air equivalence ratio and fuel composition, to identify the states of the combustion depending on the operation conditions. Tinaut et al [20] characterized $\mathrm{OH}^{*}$ and $\mathrm{CH}^{*}$ chemiluminescent emissions in $\mathrm{n}$-heptane, iso-octane and $\mathrm{n}$-heptane/toluene flames inside a constant volume combustion bomb, thus allowing to raise the combustion pressure. They found that the ratio $\mathrm{OH}^{*} / \mathrm{CH}^{*}$ was proportional to the equivalence ratio. In the early work of Clark et 
al. [22, 23], they studied the chemiluminescence emitted during the combustion in a spark ignition (SI) internal combustion engine and established that the intensity of each component depended on the fuel and on the initial equivalence ratio. The detection of $\mathrm{OH}^{*}$ chemiluminescence has been used as a diagnostic tool by Lee et al. [24]. Lawn [25] developed some tests in swirl burners studying the relationship between the $\mathrm{OH}^{*}$ chemiluminescence at $306.4 \mathrm{~nm}$ and the rate of heat release during the combustion of two fuels: methane and propane. In both cases they found that the $\mathrm{OH}^{*}$ chemiluminescence was proportional to the rate of heat release during the combustion. Additionally, De Leo et al. [26] studied the chemiluminescence emitted by $\mathrm{OH}^{*}$ and $\mathrm{CH}^{*}$ radicals in a burner fuelled with methane, and concluded that both radicals were the most numerous in hydrocarbon flames. They also found a correlation between the rate $\mathrm{OH}^{*} / \mathrm{CH}^{*}$ and the rate of heat release during the combustion. Some authors also use the rate of heat release (RoHR) as an estimator of the combustion intensity. The works by Clark et al. [22] and Price et al. [10] can be considered as the first evidence of the relationship between the RoHR. Since then, several studies have been developed in different experimental facilities, confirming the correlation between the RoHR and the chemiluminescence emitted by chemical radicals, which are important during the combustion process, Tinaut et al. [20], Nori et al. [27], Lauer M. [28], between others. All these references are included in the methodology text.

This paper is focused on the study of the premixed combustion process of different mixtures of methane and hydrogen (in different proportions) under different conditions of pressure and temperature. The study includes not only the analysis of pressure trace, but also the $\mathrm{OH}^{*}$ and $\mathrm{CH}^{*}$ chemiluminescence radiation emitted during the combustion process. Pressure curves are experimentally obtained during each combustion event in a constant volume combustion bomb. The burning velocity and unburned temperature are 
obtained from the pressure by making use of a diagnosis model. Burning velocities are obtained under the consideration of a smooth spherical flame front. In some conditions the flame front is strictly laminar, while in other some cellularity may appear [29]. The obtained burning velocities are compared with results obtained by other authors.

$\mathrm{OH}^{*}$ and $\mathrm{CH}^{*}$ chemiluminescence emissions are acquired with different photomultipliers positioned in an optical access. The morphology of the $\mathrm{OH}^{*}$ and $\mathrm{CH}^{*}$ chemiluminescence curves obtained in the constant volume combustion bomb are described and investigated. Finally these plots are used in order to establish some relationships between these emissions and the flame temperature and rate of heat release. Other authors have studied the combustion of hydrogen and methane mixtures through the pressure and burning velocity, however the present research adds new results obtained with $\mathrm{OH}^{*}$ and $\mathrm{CH}^{*}$ chemiluminescence signals in a constant volume combustion bomb, i.e., with a pressure range extended up to $2.5 \mathrm{MPa}$. 


\section{Methodology}

\subsection{Experimental setup and procedure}

The main component of the experimental facility is a constant volume combustion bomb (CVCB), a stainless steel spherical cavity of 0.2 meters of diameter, which has been designed to withstand pressures up to $40 \mathrm{MPa}$ and temperatures up to $1073 \mathrm{~K}$ during the combustion development. The ignition of the mixture is originated at the centre of the sphere by a spark between two electrodes. This facility is designed for the study and characterization of liquid and gaseous fuel combustion processes under different conditions. In Figure 1i is shown a sketch of the experimental setup

In each test, the initial conditions of pressure, temperature can be set at the beginning of each combustion. A piezoelectric pressure transducer (Kistler type 7063) registers the pressure in the chamber during combustion.

In order to detect the chemiluminescence emitted by the excited chemical radicals during the combustion, the CVCB has two small orifices for optical accesses, one radial pointing at the centre of the CVCB and a second one horizontal, see Figure 1ii. In this work only the horizontal access has been used. A beam splitter is used with two photomultipliers to simultaneously register the $\mathrm{OH}^{*}$ and $\mathrm{CH}^{*}$ emissions along the same optical way.

Two Hammamatsu 9536 photomultipliers are used for the $\mathrm{OH}^{*}$ and $\mathrm{CH}^{*}$ chemiluminescence detection at $306 \mathrm{~nm}$ and $430 \mathrm{~nm}$, respectively. More details of the experimental installation and methodology can be seen in Tinaut et. al. [20] 
The registered values of pressure-time are treated by means of an analysis model of the combustion based on the energy, volume, mass conservation and ideal gas equations [30]. The model is based on dividing the combustion chamber in two different zones: burned and unburned, and the application of the conservation and ideal gas equations in each zone. During combustion, the unburned zone converts into burned zone, which starts at the geometric centre of the sphere from the ignition caused by a spark plug. Thus the burned zone grows spherically in a concentric way with the vessel wall. The main inputs of the analysis model are the temporal evolution of the registered pressure during the combustion, the fuel composition and the mass of the gaseous mixture. Among other variables, the outputs of this model are the temperatures of the unburned mixture and burned zone, the burned mass fraction (BMF), the flame front surface and the burning velocity [30], [31]. The burning velocity is calculated from the mass burning rate, the unburned mixture density and the flame front surface $A_{f}$, according to the following expression:

$$
u_{c l}=\frac{m_{b}}{\rho_{u b} A_{f}}
$$

In general, many authors use the rate of heat release (RoHR) as an estimator of the combustion intensity $[10,22,23,27,28,32]$. In the present work, a two-zone diagnostics model is used to determine the burned mass fraction rate, BMFR (burned mass rate normalized with the total mass). Additionally, the RoHR is also calculated from the apparent heat release during combustion, normalised with the maximum possible heat release (fuel mass times its heating value) as:

$$
R o H R=\frac{d Q / d t}{m_{f} H_{f}}
$$

The apparent heat release is computed on the basis of the First Law of 
Thermodynamics applied to a single zone, for a quasi-static system, i.e., with uniform pressure and mean temperature at any instant in time (see eq. 3), where $\gamma$ is the mean adiabatic coefficient:

$$
\frac{d Q}{d t}=\frac{1}{\gamma-1} V \frac{d p}{d t}
$$

It is possible to explore relationships between the values of the variables representative of the combustion process, both experimentally registered (as the pressure or the chemiluminescence emissions) and analytically obtained (as the temperatures and ROHR). These relationships can be used to develop diagnosis tools of combustion devices.

\section{2. Chemiluminescence study}

Hydroxyl radical chemiluminescence arises from the emission of light of the electronically excited $\mathrm{OH} \mathrm{A}{ }^{2} \Sigma^{+}$(denoted as $\mathrm{OH}^{*}$ in flame chemiluminescence literature) which is observed in the ultraviolet zone of the electromagnetic spectrum. The main $\mathrm{OH}^{*}$ emissions are at the wavelengths: $281 \mathrm{~nm}, 306-320 \mathrm{~nm}$ and $340-348 \mathrm{~nm}$, with the most intense peaks at $306 \mathrm{~nm}$ and $281 \mathrm{~nm}$. The knowledge of the chemical reactions that cause the chemiluminescence signal detected in the experiments is important to interpret results. First, it must be recalled that the three main mechanisms of $\mathrm{OH}^{*}$ production $[13,33]$ are the following:

1. Excitation in the flame front of hydrocarbons combustion which leads to high temperatures, as proposed by Krishnamachari et al. [34] in 1961 and used by 
Dandy et al [35]in 1992. This is one of the most likely mechanisms for the production of $\mathrm{OH}^{*}\left({ }^{2} \sum^{+}\right)$in the flame, where $\mathrm{OH}^{*}$ radicals are produced by the oxidation of $\mathrm{CH}[14,20,36]$ :

$\mathrm{CH}+\mathrm{O}_{2} \rightarrow \mathrm{CO}+\mathrm{OH}^{*}\left({ }^{2} \sum^{+}\right)$

2. Some chemi-excitation of $\mathrm{OH}$ by the recombination of radicals in the low temperature reaction zone of hydrocarbon flames:

$\mathrm{H}+\mathrm{OH}+\mathrm{OH} \rightarrow \mathrm{H}_{2} \mathrm{O}+\mathrm{OH}^{*}$

3. Anomalous excitation of the vibration energy levels of hydrogen atom in hydrogen flames due to an inverse predissociation:

$\mathrm{O}+\mathrm{H} \rightarrow \mathrm{OH} *\left({ }^{4} \sum^{-}\right) \rightarrow O H^{*}\left({ }^{2} \sum^{+}\right)$

Hydroxyl radicals exist in both the flame front and the hot postcombustion gases. The best techniques for detection are absorption, chemiluminescence and laser-induced fluorescence [37].

$\mathrm{CH}^{*}$ chemiluminescence emissions appear in three emission bands: 417-447 nm, 472$491 \mathrm{~nm}$ and $362-371 \mathrm{~nm}$. The more intense emission is detected at $431 \mathrm{~nm}$, due to the transition $\left(\mathrm{A}^{2} \Delta \rightarrow \mathrm{X}^{2} \Pi\right)$, mainly generated by two reactions, eqs, 7 and 8 .

1. The reaction of $\mathrm{C}_{2} \mathrm{H}$ with atomic oxygen:

$$
C_{2} H+O\left({ }^{3} P\right) \rightarrow C O+C H *\left(\mathrm{~A}^{2} \Delta\right)
$$

2. The recombination of different radicals:

$$
\mathrm{CH}+\mathrm{CO}+\mathrm{H} \rightarrow \mathrm{CH}^{*}+\mathrm{H}_{2} \mathrm{O}
$$

$\mathrm{CH}^{*}$ chemiluminescence near $431 \mathrm{~nm}$ arises from the excited state $\mathrm{CH}^{*}\left[\mathrm{CH}\left(\mathrm{A}^{2} \Delta\right)\right]$ produced primarily through the reaction of $\mathrm{C}_{2} \mathrm{H}$ with molecular oxygen, [14, 38], which is the most representative for low-pressure flames, eq. 7. However, for rich flames it is 
necessary to take into account the decomposition of the $\mathrm{HCO}^{*}$ and the peroxide formation (eq. 8) $[1,13]$.

The resulting $\mathrm{OH}^{*}$ and $\mathrm{CH}^{*}$ radicals in an electronically excited state lose their energy through either spontaneous fluorescence (chemiluminescence) or by physical collisions (quenching).

In this work, $\mathrm{OH}^{*}$ chemiluminescence is measured with a photo-multiplier tube (PMT) with a band-pass interference filter centred at $307.1 \mathrm{~nm}$, with a $25 \mathrm{~nm}$ full-width halfheight, FWHM. In order to measure $\mathrm{CH}^{*}$ chemiluminescence, a second PMT is used in combination with a band-pass interference filter centred at $430.0 \mathrm{~nm}$ with a FWHM of $10 \mathrm{~nm}$.

The intensity of chemiluminescence is measured in lumens ( $1 \mathrm{~m}$ or better nlm $\left[10^{-9} \mathrm{~lm}\right]$ or plm $\left.\left[10^{-12} \mathrm{~lm}\right]\right)$. The conversion factor is obtained with the correlation curve of the PMTs as a function of the input voltage.

The results of the $\mathrm{OH}^{*}$ chemiluminescence emissions obtained in this work present a relatively high level of noise; for that reason, the curves are presented with a high resolution smoothing, as can be seen in Figure 2.

The chemiluminescence emitted during a combustion process has two contributions: the flame front contribution, basically formed by discrete emissions from $\mathrm{OH}^{*}, \mathrm{CH}^{*}$ and $\mathrm{C}_{2}$ * radicals, and the continuous emission originated by the hot gases during the postcombustion period, usually called afterglow emissions, [11]. Figure 3 shows an example of the pressure, $\mathrm{OH}^{*}$ and $\mathrm{CH}^{*}$ chemiluminescence emissions registered during a combustion of $50 \%$ hydrogen and $50 \%$ natural gas, at $0.45 \mathrm{MPa}, 458 \mathrm{~K}$ initial conditions and 0.8 equivalence ratio. In the figure, the combustion and postcombustion periods are delimited by the vertical dashed line. During the combustion process, the flame front grows from the bomb centre, as the burned mass and pressure increase. The 
pressure reaches its maximum value at the end of combustion, as the flame front arrives to the inner part of the bomb wall. When that happens, heat transfer increases and the burned gases temperature and pressure reduce in the afterglow region. $\mathrm{OH}^{*}$ and $\mathrm{CH}^{*}$ emissions (detected by the horizontal optical orifice, Figure 1) increase as the combustion progresses in the CVCB. It must be noticed that, due to the horizontal orientation of the photomultipliers, chemiluminescence signals only can be detected once the flame front has a radius bigger than the vertical distance between the photomultiplier and the bomb centre. The $\mathrm{OH}^{*}$ chemiluminescence emission reaches its maximum value near the point of maximum pressure, while the $\mathrm{CH}^{*}$ chemiluminescence has a small delay with respect to the $\mathrm{OH}^{*}$ curve. The absolute scale of $\mathrm{CH}^{*}$ are almost two orders of magnitude bigger than that of $\mathrm{OH}^{*}$. For both radicals, afterglow emissions are strong and keep a relatively long time after the end of combustion.

\section{Results and discussion}

In this section, the effect of hydrogen addition on the flame propagation process of methane premixed combustion in the CVCB is analysed. The initial conditions of the experiments with mixtures of hydrogen/methane are detailed in Table 1. Experiments with different percentages of hydrogen in the fuel mixture $(0,3,6,15,30,50,75$ and $100 \%)$ were carried out at atmospheric initial conditions $(\mathrm{T}=300 \mathrm{~K}, \mathrm{p}=0.10 \mathrm{MPa}$ and fuel/air equivalence ratio of 0.8 , denominated A.1 to A.8 in Table 1) to examine the influence of hydrogen addition on the burning velocity of methane. Then, additional tests were made with initial conditions at higher pressure and temperature, denominated as intermediate conditions (about $0.46 \mathrm{MPa}$ and $458 \mathrm{~K}$, called I.1 to I.8 in Table 1). 
For each experiment, initial pressure and temperature are set at the specific values of Table 1. Once, the combustion starts by the spark plug, pressure increases and also temperature in the unburned zone due to quasi-adiabatic compression in the CVCB, as can be seen in Figure 4. The plots of the evolution of the unburned zone temperature versus the pressure for each individual experiment, computed with the two-zone combustion model, are shown in this Figure. In fact, this Figure represents the range of experimental conditions covered in the study, both the initial conditions of Table 1 and the conditions reached due to combustion development from these initial conditions $(0.1$ to 2.5 MPa, with unburned temperature $300-700 \mathrm{~K}$ ).

It can be observed that the thermodynamic conditions (pressure and temperature) of the tests with more elevated initial conditions of pressure and temperature (I.1 to I.8) show continuity and overlap with the thermodynamic conditions of tests performed at atmospheric initial conditions (A.1 to A.8). The fact of this overlapping is a proof of the repetitiveness of the whole experimental procedure. For each of the conditions considered in Table 1, a set of three experiments was made to confirm and verify the repetitiveness of the experimental procedure.

In the following sections, results corresponding to pressure and burning velocity are first presented. Then, the burning velocities of hydrogen/methane mixtures are compared with results published in the bibliography. Finally, the morphology of $\mathrm{OH}^{*}$ and $\mathrm{CH}^{*}$ chemiluminescence curves is described and studied in detail.

\subsection{Influence of the hydrogen content on the combustion development}

An investigation of the influence of hydrogen content on the methane/air blend is made 
through the characterization of the combustion pressure curve, burning velocity and chemiluminescence emissions.

First, in Figure 5 the temporal evolution of the pressure curve during the combustion process is represented for each test with different initial pressure and temperature conditions and the percentages of hydrogen in the blend (conditions of Table 1). The shape of the pressure curve has two different parts, initially a growing part corresponding to the development of the flame front during the combustion until the maximum pressure is reached, and followed by a decreasing zone corresponding to a cooling zone when the combustion has finished.

As can be seen in Figure 5, as the percentage of hydrogen increases in the mixture, pressure increases faster, according to a higher burning velocity. For initial ambient conditions (Figure 5i, for conditions A.1 to A.8), the pressure peak tends to increase as the percentage of hydrogen increases in the mixture. However, for medium pressure and temperature conditions (Figure 5ii, and conditions I.1 to I.) the tendency is the contrary, with the curve of $100 \%$ of hydrogen presenting the lower pressure peak. This can be explained as a result of the complex interaction among the pressure, the temperature and the specific heat of the reacting mixture. When the hydrogen fraction changes, the lower heating value, stoichiometric fuel/air ratio, molar weight and specific heat of the fuel mixture change, with the resulting combined effect shown in Figure 5.

It is worth mentioning that near the end of the combustion process, and in the proximity of the pressure peak, pressure curves of pure hydrogen show high frequency oscillations. Von Elbe and Lewis [39] and Garforth and Rallis [40] observed these oscillations in some explosions in closed vessels due to gaseous vibrations due to excitation delays. This is a typical process at low temperature explosions which appear when temperature increases suddenly in internal parts of the burned kernel. Dahoe [41] 
explains the oscillations in the hydrogen pressure curve through the inversion of the particles movement near the vessel walls. Iijima and Takeno [42] detected oscillations in the hydrogen pressure curve when the pressure reaches five or seven times the initial pressure of the experiment, caused by detonation waves. Bradley et al. [43] explain these oscillations as acoustic interactions. Gabano et al. [44] described this oscillations caused by acoustic waves pressure as a result of the hydrodynamic instabilities of the flame front with the vessel walls.

The corresponding burning velocities have been calculated from the pressure curves presented in Figure 5 with the two-zone diagnosis model. Thus, velocities are obtained as functions of time. A more convenient way of representing the burning velocities is plotting them as functions of unburned zone temperature, as is made in Figure 6. The results corresponding to ambient initial conditions of pressure and temperature are plotted in figure 6i (left: A.1 to A.8; right: zoom of conditions A.1 to A.5) and those for higher conditions of pressure and temperature are represented in figure 6ii (left: I.1 to I.8; right: zoom of conditions I.1 to I.5). In general, it can be seen in Figure 6 that burning velocities increase as the percentage of hydrogen in the fuel blend grows, as it could be expected from the increasingly steeper pressure plots of Figure 5.

It has been questioned whether a hydrogen/methane flame has a laminar or cellular character, since the effect of the hydrogen on the combustion velocity enhances the apparition of instabilities (Serrano et al. [45], Mandilas et al. [46] and Marley and Roberts [47]). In the right upper part of Figure 6 (conditions A.1 to A.5), corresponding to ambient initial conditions, it can be seen a characteristic bump in the last part of the burning velocity plot, for high values of unburned temperature. This bump is associated to the transition from laminar to cellular conditions, shown as an increment of the 
apparent burning velocity. It can be observed that the position of this characteristic bump is displaced towards smaller unburned temperatures as the hydrogen content increases (from blue to red line). For higher percentages of hydrogen (left upper part of Figure 6, conditions A.6 to A.8), this trend cannot be identified, since the hydrogen effect probably causes a cellular flame from the beginning of the combustion. Similar effect appears when the initial conditions are higher, although for all hydrogen contents (I.1 to I.8, lower part of Figure 6). A more detailed discussion of this effect can be found in Reyes et al. [48].

\subsection{Comparison of burning velocities with other authors' results}

In this section, burning velocity results of hydrogen/methane mixtures are compared with other results published in the literature. Burning velocity takes a different value for each pair of pressure and temperature, as can be seen in Figure 6. It is then possible to adjust the burning velocity values by means of a correlation as a function of pressure and temperature, similar to the correlation proposed by Metghalchi-Keck [49]. The adjusted correlation provides a value for the burning velocity at any condition of pressure and temperature, in its range of validity. In particular, the values can be computed for a 0.10 MPa pressure and $300 \mathrm{~K}$ temperature. These values are plotted in Figure 7 for different percentages of hydrogen, with the fixed equivalence ratio of 0.8 . They are compared with the values published by Coppens et al.[50], Huang et al. [5], Tanoue et al. [51] and Bougrine et al. [52]. It is possible to see that the authors' results are in an agreement with the rest of data.

3.3. Study of the $\mathrm{OH}^{*}$ and $\mathrm{CH}^{*}$ chemiluminescence emitted by hydrogen/methane 
In this section the $\mathrm{OH}^{*}$ and $\mathrm{CH}^{*}$ chemiluminescence curves are presented and their morphology is investigated as a function of the hydrogen content in the blend.

The time evolutions of pressure, $\mathrm{OH}^{*}$ and $\mathrm{CH}^{*}$ chemiluminescence emissions in combustions of hydrogen/methane at initial ambient conditions of pressure and temperature are represented in Figure 8. In the upper part of Figure 8 the plots are represented for ambient initial conditions (A.1 to A.8), while in the lower part the ones for intermediate initial conditions (I.1 to I.8) are shown. On the left side the plots shown are for high percentages of hydrogen $(100,75,50 \%)$, while on the right side, the plots correspond to the cases of low hydrogen content $(0,3,6,15,30 \%)$.

From these figures, it is possible to see that the maximum value of the $\mathrm{OH}^{*}$ chemiluminescence is reached near the maximum value of the pressure, i.e., during the combustion process. Vertical lines in Figure 8 mark the end of the combustion process; they establish a separation between the combustion and the afterglow emissions. It is possible to see that once the maximum value of $\mathrm{OH}^{*}$ is reached, this chemiluminescence also appears in the post-combustion process, but with decreasing intensity until extinction.

In Figure 8 it is also possible to see that the $\mathrm{OH}^{*}$ chemiluminescence emissions increase as the percentage of hydrogen increases in the mixture. This increment is more noticeable when the percentage of hydrogen exceeds of 50\%. Nilsson et al. [53] also observe the increment in the $\mathrm{OH}$ concentration as the flame is enriched with hydrogen. A comparison of plots for low $\mathrm{H}_{2}$ percentages (right side) and high $\mathrm{H}_{2}$ content (left side) shows that $\mathrm{OH}^{*}$ chemiluminescence increases by a factor of about five. 
In all cases, the chemiluminescence curves in Figures 8 confirm that $\mathrm{OH}^{*}$ radicals that are present in the flame front keep emitting from hot post-combustion gases, during a time period of about $100 \mathrm{~ms}$. This time associated to the after-glow emissions is relatively independent of the actual combustion time, which in turn is strongly dependent on the hydrogen content. When hydrogen is added to a methane flame some fast reactions are activated [54] which can enhance the local production of $\mathrm{OH}^{*}$ chemiluminescence, mainly in the reaction zone through the first and second mechanisms of $\mathrm{OH}^{*}$ production (equations (3) and (4)). This effect becomes apparent in this work, since chemiluminescence is detected through a horizontal optical access placed at $8 \mathrm{~cm}$ above the centre of the combustion chamber, and then the radiation signal comes mainly from the reaction zone.

Similarly to the case of $\mathrm{OH}^{*}, \mathrm{CH}^{*}$ chemiluminescence intensity increases strongly (by a factor of 5 to 10) as the hydrogen content increases in the blends. Again the shape of the plots shows that $\mathrm{CH}^{*}$ radiation exists both during combustion and in the afterglow region during the post-combustion process of the $\mathrm{CO}$ in $\mathrm{CO}_{2}$. In fact, the positions of $\mathrm{CH}^{*}$ peaks are delayed from combustion pressure peaks, a fact that is more noticeable in the experiments with the intermediate initial conditions (lower part of Fig. 8). The afterglow emission has been detected by numerous authors, firstly by Withrow and Rassweiler in the 1931 [11] and confirmed by other works [55-57].

In the $\mathrm{CH}^{*}$ emissions for the experiments at ambient initial conditions (A.1 to A.8), an increment in $\mathrm{CH}^{*}$ chemiluminescence emissions is detected when the percentage of hydrogen increases from 0 to $100 \%$. It could be expected that when the percentage of hydrogen increases in the mixture, $\mathrm{CH}^{*}$ chemiluminescence emissions should reduce because $\mathrm{CH}$ and $\mathrm{C}_{2} \mathrm{H}$ radicals concentration decrease and even they should become 
null for $100 \% \mathrm{H}_{2}$. In literature, some authors have studied $\mathrm{CH}^{*}$ chemiluminescence in continuous burners, for example, Schefer et al. [58]. They also obtain an increment in $\mathrm{CH}^{*}$ emissions at the measured frequency $(430 \mathrm{~nm})$ by the radiation due to two alternative sources. According to their argument, radiation detected with the PMT sensor at $430 \mathrm{~nm}$ is not only due to $\mathrm{CH}^{*}$ chemiluminescence, but it also includes radiation coming from other reactions of molecular and atomic hydrogen. The first alternative source of emission is due to molecular hydrogen in the region of 410-477 $\mathrm{nm}$, while the second is due to the emission of atomic hydrogen at $434.05 \mathrm{~nm}(2 \mathrm{p}-5 \mathrm{~d}$ transition). In another study, also for continuous combustion, Ballester et al. [21] and [59] detected a background radiation in the band 190-1100 $\mathrm{nm}$ which increases as the percentage of hydrogen increases in the fuel mixture. Both explanations justify the increment of the $\mathrm{CH}^{*}$ chemiluminescence emission presently detected for all blends as the hydrogen contents is higher, but especially when the percentage of hydrogen in the mixture is higher than $50 \%$.

The value of the peak $\mathrm{CH}^{*}$ emissions are represented in Figure 9 versus the percentage of hydrogen in the fuel blend, for different initial conditions to study in detail the effect of hydrogen content on the $\mathrm{CH}^{*}$ chemiluminescence emissions. In this Figure it can be seen that as the percentage of hydrogen in the mixture increases, the maximum values of $\mathrm{CH}^{*}$ emission slightly grow, but when the percentage of hydrogen exceeds of $75 \%$ for ambient initial conditions and from $50 \%$ for the intermediate initial conditions, their value increase strongly. It should be noticed that the trend of $\mathrm{CH}^{*}$ emission maxima is similar to that of burning velocities (Fig. 7). 
Some relationships can be found between $\mathrm{OH}^{*}$ and $\mathrm{CH}^{*}$ chemiluminescence emissions and other variables of interest during the combustion process: flame temperature and rate of heat release (RoHR), in particular between the times at which the maxima of these three variables appear.

The maxima of $\mathrm{OH}^{*}$ emissions are determined from the original $\mathrm{OH}^{*}$ curves taking into account only the emissions due to the combustion process but not those of the afterglow period. In Figure 10 the time at which the maximum rate of heat release during each combustion experiment (RoHRmax) is reached is represented versus the time at which the maximum $\mathrm{OH}^{*}$ chemiluminescence emissions time is achieved, for combustions of hydrogen/methane mixtures in different proportions, for both atmospheric initial conditions (red squares: A.1 to A. 8) and intermediate pressure and temperature initial conditions (black triangles: I.1 to I.8) It is possible to see that $\mathrm{OH}^{*}$ chemiluminescence peaks are slightly delayed relative to RoHR peaks, but with a strong linear relationship between both variables. That implies that $\mathrm{OH}^{*}$ radiation can be considered a good tracer of the RoHR. Same results have been found by other authors in the literature, for example, Lawn [25] and De Leo et al. [26] confirming this assertion.

A second important relationship can be established between the times at which flame temperature and $\mathrm{CH}^{*}$ chemiluminescence reach their maxima. In general, in premixed flames, $\mathrm{CH}^{*}$ chemiluminescence is a good indicator of the flame front position because it is at the flame front where the $\mathrm{CH}^{*}$ radicals are mainly generated and where the high temperature reactions take place $[13,60]$. The flame temperature considered in this analysis is the burned-zone temperature calculated with the combustion two-zone 
model. In Figure 11, the time at which the maximum flame temperature is reached, is plotted versus the time of the peak $\mathrm{CH}^{*}$ chemiluminescence emission in the combustions of hydrogen/methane at different initial conditions. Since both maxima practically coincide for all experimental conditions, $\mathrm{CH}^{*}$ chemiluminescence emissions can be considered a good marker of the flame front position in the combustion bomb.

\section{Conclusions}

The investigation consists of an experimental study of the combustion pressure and the $\mathrm{OH}^{*}$ and $\mathrm{CH}^{*}$ chemiluminescence emitted during premixed combustion of methane/air mixtures blended with different percentages of hydrogen $(0,3,6,15,30,50,75$ and $100 \%$ ) at two sets of initial conditions of pressure and temperature (ambient: $0.1 \mathrm{MPa}$ and $300 \mathrm{~K}$, and intermediate: $0.46 \mathrm{MPa}$ and $458 \mathrm{~K}$ ), for a given fuel/air ratio of 0.8 . Starting from these initial conditions, the results cover a pressure range from 0.1 to 2.5 $\mathrm{MPa}$, associated to an unburned temperature range from 300 to $700 \mathrm{~K}$. These ranges are further the limits of previously published works, usually covering near atmospheric pressures.

The burning velocity, heat release rate and unburned/burned temperatures are calculated from the registered pressure by means of a two-zone thermodynamic diagnosis model. This model is based on the application of mass and energy conservation to the unburned and burned zones of the combustion bomb, by using the experimental combustion pressure as input data.

It can be seen in the $\mathrm{OH}^{*}$ and $\mathrm{CH}^{*}$ chemiluminescence emissions curves that smaller percentages of hydrogen in the mixture (less than 50\%) bring a slight increase of detected radiation, in agreement with the associated acceleration of the combustion 
development. However, $\mathrm{OH}^{*}$ and $\mathrm{CH}^{*}$ chemiluminescence emissions are strongly enhanced when the percentage of hydrogen in the methane-air mixture exceeds respectively of $50 \%$ and $75 \%$.

The morphology of the $\mathrm{OH}^{*}$ and $\mathrm{CH}^{*}$ curves investigated shows different patterns for $\mathrm{OH}^{*}$ and $\mathrm{CH}^{*}$ emissions. $\mathrm{OH}^{*}$ emissions (registered at $307 \mathrm{~nm}$ ) reach their maximum value near the end of the combustion process (for both low and intermediate conditions of pressure and temperature), while $\mathrm{CH}^{*}$ emissions (registered at $430 \mathrm{~nm}$ ) show their maximum values after the end of the combustion, in the afterglow period. This pattern is more noticeable in the experiments developed at lower conditions of pressure and temperature.

The results show that $\mathrm{OH}^{*}$ and $\mathrm{CH}^{*}$ chemiluminescence emissions can be used to monitorize and diagnose combustion processes of $\mathrm{H}_{2}$ /methane-air, since the peak value of $\mathrm{OH}^{*}$ chemiluminescence correlates well with the point of maximum rate of heat release, while the $\mathrm{CH}^{*}$ chemiluminescence is a good indicator of the flame front position. It must be noticed that even fuel-air mixtures with pure hydrogen present chemiluminescence emissions at the frequency associated to $\mathrm{CH}^{*}(430 \mathrm{~nm})$, due to radiation from molecular and atomic hydrogen. 
$\mathrm{A}_{\mathrm{f}} \quad$ flame front surface $\left(\mathrm{m}^{2}\right)$

CVCB constant volume combustion bomb

ICE internal combustion engine

$\mathrm{F}_{\mathrm{r}} \quad$ fuel/air equivalence ratio (-)

h Planck constant

$\mathrm{H}_{\mathrm{f}} \quad$ lower heating value of the fuel $(\mathrm{J} / \mathrm{kg})$

m mass $(\mathrm{kg})$

NG natural gas

$\mathrm{p} \quad$ pressure $(\mathrm{Pa})$

PMT photomultiplier tube

Q heat release $(\mathrm{J})$

RoHR rate of heat release (-)

$\mathrm{T} \quad$ temperature $(\mathrm{K})$

$\mathrm{t} \quad$ time $(\mathrm{s})$

u burning velocity $(\mathrm{m} / \mathrm{s})$

V volume $\left(\mathrm{m}^{3}\right)$

\section{GREEK:}

$\Phi \quad$ chemiluminescence (lm or plm)

$\gamma \quad$ adiabatic constant

${ }^{\mathrm{a}} \Sigma^{\mathrm{a}} \quad$ determined excited state

$v \quad$ frequency $(\mathrm{nm})$

$\rho \quad$ density $\left(\mathrm{kg} / \mathrm{m}^{3}\right)$ 
SUBSCRIPTS:

a air

b burned

f flame front

i initial

$\max$ maximum

ub unburned

* excited radical 


\section{References}

[1] Naber JD, Siebers DL, Di Julio SS, Westbrook CK. Effects of natural gas composition on ignition delay under diesel conditions. Combustion and Flame. 1994;99:192-200.

[2] El-Sherif AS. Effects of natural gas composition on the nitrogen oxide, flame structure and burning velocity under laminar premixed flame conditions. Fuel. 1998;77:1539-47.

[3] Bauer CG, Forest TW. Effect of hydrogen addition on the performance of methanefueled vehicles. Part I: effect on S.I. engine performance. International Journal of Hydrogen Energy. 2001;26:55-70.

[4] Wang J, Huang Z, Zheng J, Miao H. Effect of partially premixed and hydrogen addition on natural gas direct-injection lean combustion. International Journal of Hydrogen Energy. 2009;34:9239-47.

[5] Huang Z, Zhang Y, Zeng K, Liu B, Wang Q, Jiang D. Measurements of laminar burning velocities for natural gas-hydrogen-air mixtures. Combustion and Flame. 2006;146:302-11.

[6] Hu E, Huang Z, He J, Jin C, Zheng J. Experimental and numerical study on laminar burning characteristics of premixed methane-hydrogen-air flames. International Journal of Hydrogen Energy. 2009;34:4876-88.

[7] Reyes M, Melgar A, Pérez A, Giménez B. Study of the cycle-to-cycle variations of an internal combustion engine fuelled with natural gas/hydrogen blends from the diagnosis of combustion pressure. International Journal of Hydrogen Energy. 2013;38:15477-87.

[8] Tinaut FV, Melgar A, Giménez B, Reyes M. Prediction of performance and emissions of an engine fuelled with natural gas/hydrogen blends. International Journal of Hydrogen Energy. 2011;36:947-56.

[9] Ikeda Y, Kojima J, Nakajima T, Akamatsu F, Katsuki M. Measurement of the local flamefront structure of turbulent premixed flames by local chemiluminescence. Proceedings of the Combustion Institute. 2000;28:343-50.

[10] Price RB, Hurle IR, Sugden TM. Optical studies of the generation of noise in turbulent flames. Symposium (International) on Combustion. 1969;12:1093-102.

[11] Withrow L, Rassweiler GM. Spectroscopic studies of engine combustion. Industrial \& Engineering Chemistry. 1931;23:769-76.

[12] Stojkovic BD, Fansler TD, Drake MC, Sick V. High-speed imaging of $\mathrm{OH}^{*}$ and soot temperature and concentration in a stratified-charge direct-injection gasoline engine. Proceedings of the Combustion Institute. 2005;30:2657-65.

[13] Gaydon AG. The spectroscopy of flames: London Champan and Hall; 1974.

[14] Najm HN, Paul PH, Mueller CJ, Wyckoff PS. On the Adequacy of Certain Experimental Observables as Measurements of Flame Burning Rate. Combustion and Flame. 1998;113:312-32.

[15] Docquier N, Lacas F, Candel S. Closed-loop equivalence ratio control of premixed combustors using spectrally resolved chemiluminescence measurements. Proceedings of the Combustion Institute. 2002;29:139-45.

[16] Nori VN, Seitzman JM. CH* chemiluminescence modeling for combustion diagnostics. Proceedings of the Combustion Institute. 2009;32:895-903.

[17] Aleiferis PG, Hardalupas Y, Taylor AMKP, Ishii K, Urata Y. Flame chemiluminescence studies of cyclic combustion variations and air-to-fuel ratio of the 
reacting mixture in a lean-burn stratified-charge spark-ignition engine. Combustion and Flame. 2004;136:72-90.

[18] Muruganandam TM, Kim BH, Morrell MR, Nori V, Patel M, Romig BW, et al. Optical equivalence ratio sensors for gas turbine combustors. Proceedings of the Combustion Institute. 2005;30:1601-9.

[19] Panoutsos CS, Hardalupas Y, Taylor AMKP. Numerical evaluation of equivalence ratio measurement using $\mathrm{OH} *$ and $\mathrm{CH} *$ chemiluminescence in premixed and nonpremixed methane-air flames. Combustion and Flame. 2009;156:273-91.

[20] Tinaut FV, Reyes M, Giménez B, Pastor JV. Measurements of $\mathrm{OH}^{*}$ and $\mathrm{CH}^{*}$ Chemiluminescence in Premixed Flames in a Constant Volume Combustion Bomb under Autoignition Conditions. Energy \& Fuels. 2011;25:119-29.

[21] Ballester J, Hernández R, Sanz A, Smolarz A, Barroso J, Pina A. Chemiluminescence monitoring in premixed flames of natural gas and its blends with hydrogen. Proceedings of the Combustion Institute. 2009;32:2983-91.

[22] Clark GL, Thee WC. Ultra-Violet Spectroscopy of Flames of Motor Fuels. Industrial \& Engineering Chemistry. 1926;18:528-31.

[23] Clark T. Studies of $\mathrm{OH}, \mathrm{CO}, \mathrm{CH}$ and $\mathrm{C} 2$ radiation from laminar and turbulent propane-air and ethylene-air flames-NACA Technical Note 4266. Technical report, National Advisory Committee for Aeronautics, Lewis Flight Propulsion Laboratory Cleveland, Ohio; 1958.

[24] Lee S-W, Tananka D, Kusaka J, Daisho Y. Two-dimensional laser induced fluorescence measurement of spray and $\mathrm{OH}$ radicals of LPG in constant volume chamber. JSAE review. 2002;23:195-203.

[25] Lawn C. Distributions of instantaneous heat release by the cross-correlation of chemiluminescent emissions. Combustion and Flame. 2000;123:227-40.

[26] De Leo M, Saveliev A, Kennedy LA, Zelepouga SA. OH and CH luminescence in opposed flow methane oxy-flames. Combustion and Flame. 2007;149:435-47.

[27] Nori V, Seitzman J. Evaluation of chemiluminescence as a combustion diagnostic under varying operating conditions. 46th AIAA Aerospace Sciences Meeting and Exhibit2008. p. 953.

[28] Lauer MRW. Determination of the heat release distribution in turbulent flames by chemiluminescence imaging: Technische Universität München; 2011.

[29] Lafuente A. Methodology for the diagnosis of the laminar burning velocity of gaseous fuel mixtures from the pressure register in a constant volume combustion bomb University of Valladolid; 2009.

[30] Reyes M. Characterization of the combustion and auto-ignition processes of liquid fuels in homogeneous mixtures for using in internal combustion engines running in HCCI mode [Ph.D. Thesis]: University of Valladolid; 2009.

[31] Horrillo A. Utilization of multi-zone models for the prediction of the pollutant emissions in the exhaust process in spark ignition engines: University of Valladolid; 1998.

[32] Tinaut F, Reyes M, Giménez B, Pastor J. Measurements of $\mathrm{OH}^{*}$ and $\mathrm{CH}^{*}$ chemiluminescence in premixed flames in a constant volume combustion bomb under autoignition conditions. Energy \& Fuels. 2010;25:119-29.

[33] Gaydon A. Applications of spectroscopy to combustion. Reports on Progress in Physics. 1941;8:50.

[34] Krishnamachari S, Broida H. Effect of Molecular Oxygen on the Emission Spectra of Atomic Oxygen-Acetylene Flames. The Journal of Chemical Physics. 1961;34:1709-11. 
[35] Dandy DS, Vosen SR. Numerical and experimental studies of hydroxyl radical chemiluminescence in methane-air flames. Combustion science and technology. 1992;82:131-50.

[36] Mancaruso E, Merola SS, Vaglieco BM. Extinction and chemiluminescence measurements in CR DI diesel engine operating in HCCI mode. SAE Technical Paper; 2007.

[37] Becker KH, Dley D, Norstrom RJ. OH* chemiluminescence in hydrocarbon atom flames. Symposium (International) on Combustion. 1969;12:405-13.

[38] Devriendt K, Van Look H, Ceursters B, Peeters J. Kinetics of formation of chemiluminescent $\mathrm{CH}(\mathrm{A} 2 \Delta)$ by the elementary reactions of $\mathrm{C} 2 \mathrm{H}(\mathrm{X} 2 \Sigma+)$ with $\mathrm{O}(3 \mathrm{P})$

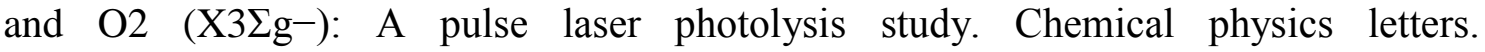
1996;261:450-6.

[39] von Elbe G, Lewis B. Comparison of ideal and actual combustion temperatures and pressures: Anomalous effects; Gas vibrations. Proceedings of the Symposium on Combustion: Elsevier; 1948. p. 220-4.

[40] Garforth AM, Rallis CJ. Gas movement during flame propagation in a constant volume bomb. Acta Astronautica. 1976;3:879-88.

[41] Dahoe AE. Laminar burning velocities of hydrogen-air mixtures from closed vessel gas explosions. Journal of Loss Prevention in the Process Industries. 2005;18:152-66.

[42] Iijima T, Takeno T. Effects of temperature and pressure on burning velocity. Combustion and Flame. 1986;65:35-43.

[43] Bradley D, Hicks RA, Lawes M, Sheppard CGW, Woolley R. The Measurement of Laminar Burning Velocities and Markstein Numbers for Iso-octane-Air and Iso-octanen-Heptane-Air Mixtures at Elevated Temperatures and Pressures in an Explosion Bomb. Combustion and Flame. 1998;115:126-44.

[44] Gabano J, Kageyama T, Fisson F, Leyer J. Experimental simulation of engine knock by means of a preheated static combustion chamber. Symposium (International) on Combustion: Elsevier; 1989. p. 447-54.

[45] Serrano C, Hernandez J, Mandilas C, Sheppard C, Woolley R. Laminar burning behaviour of biomass gasification-derived producer gas. International Journal of Hydrogen Energy. 2008;33:851-62.

[46] Mandilas C, Ormsby M, Sheppard C, Woolley R. Effects of hydrogen addition on laminar and turbulent premixed methane and iso-octane-air flames. Proceedings of the Combustion Institute. 2007;31:1443-50.

[47] Marley S, Roberts W. Measurements of laminar burning velocity and Markstein number using high-speed chemiluminescence imaging. Combustion and Flame. 2005;141:473-7.

[48] Reyes M, Tinaut FV, Horrillo A, Lafuente A. Experimental characterization of burning velocities of premixed methane-air and hydrogen-air mixtures in a constant volume combustion bomb at moderate pressure and temperature. Applied Thermal Engineering. 2017.

[49] Metghalchi M, Keck JC. Burning velocities of mixtures of air with methanol, isooctane, and indolene at high pressure and temperature. Combustion and Flame. 1982;48:191-210.

[50] Coppens FHV, De Ruyck J, Konnov AA. Effects of hydrogen enrichment on adiabatic burning velocity and NO formation in methane + air flames. Experimental Thermal and Fluid Science. 2007;31:437-44. 
[51] K. Tanoue SG, F. Shimada, T. Hamatake. Effects of hydrogen addition on stretched premixed laminar methane flames. 1st Report, effects on laminar burning velocity. Transactions of JSME. 2003;69:162-8.

[52] Bougrine S, Richard S, Nicolle A, Veynante D. Numerical study of laminar flame properties of diluted methane-hydrogen-air flames at high pressure and temperature using detailed chemistry. International Journal of Hydrogen Energy. 2011;36:12035-47.

[53] Nilsson EJK, van Sprang A, Larfeldt J, Konnov AA. The comparative and combined effects of hydrogen addition on the laminar burning velocities of methane and its blends with ethane and propane. Fuel. 2017;189:369-76.

[54] Oh J, Noh D, Ko C. The effect of hydrogen addition on the flame behavior of a non-premixed oxy-methane jet in a lab-scale furnace. Energy. 2013;62:362-9.

[55] Rassweiler GM, Withrow L. Emission spectra of engine flames. Industrial \& Engineering Chemistry. 1932;24:528-38.

[56] Kirkbright G, West T. The application of separated flames in analytical flame spectroscopy. Applied optics. 1968;7:1305-11.

[57] Ikeda Y, Nishihara H, Nakajima T. Detailed spectrum analysis of chemiluminescent radicals at flame front in a SI engine. The 5th international symposium on diagnostics and modelling of combustion in internal combustion engines, COMODIA Nagoya Japan2001.

[58] Schefer RW, Kulatilaka WD, Patterson BD, Settersten TB. Visible emission of hydrogen flames. Combustion and flame. 2009;156:1234-41.

[59] García-Armingol T, Ballester J. Influence of fuel composition on chemiluminescence emission in premixed flames of $\mathrm{CH} 4 / \mathrm{CO} 2 / \mathrm{H} 2 / \mathrm{CO}$ blends. International Journal of Hydrogen Energy. 2014;39:20255-65.

[60] Hernandez J, Sanz-Argent J, Benajes J, Molina S. Selection of a diesel fuel surrogate for the prediction of auto-ignition under HCCI engine conditions. Fuel. 2008;87:655-65. 
Table 1. Initial conditions of the combustion experiments with hydrogen/methane blends

\begin{tabular}{|c|c|c|c|c|c|c|}
\hline Case & $\mathrm{CH}_{4}$ & $\mathrm{H}_{2}$ & $\mathrm{p}_{\mathrm{i}}(\mathrm{MPa})$ & $\mathrm{T}_{\mathrm{i}}(\mathrm{K})$ & $\mathrm{F}_{\mathrm{r}}$ & \\
\hline 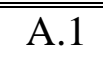 & $100 \%$ & $0 \%$ & 0.10 & 300 & 0.8 & \multirow{8}{*}{ 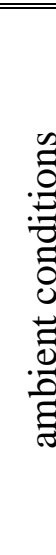 } \\
\hline A. 2 & $97 \%$ & $3 \%$ & 0.10 & 300 & 0.8 & \\
\hline A. 3 & $94 \%$ & $6 \%$ & 0.10 & 300 & 0.8 & \\
\hline A. 4 & $85 \%$ & $15 \%$ & 0.10 & 300 & 0.8 & \\
\hline A.5 & $70 \%$ & $30 \%$ & 0.10 & 300 & 0.8 & \\
\hline A.6 & $50 \%$ & $50 \%$ & 0.10 & 300 & 0.8 & \\
\hline A. 7 & $25 \%$ & $75 \%$ & 0.10 & 300 & 0.8 & \\
\hline A. 8 & $0 \%$ & $100 \%$ & 0.10 & 300 & 0.8 & \\
\hline I.1 & $100 \%$ & $0 \%$ & 0.46 & 458 & 0.8 & \multirow{8}{*}{ 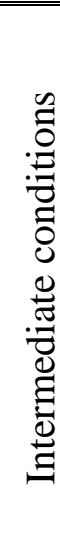 } \\
\hline I. 2 & $97 \%$ & $3 \%$ & 0.46 & 457 & 0.8 & \\
\hline I.3 & $94 \%$ & $6 \%$ & 0.46 & 458 & 0.8 & \\
\hline I. 4 & $85 \%$ & $15 \%$ & 0.46 & 458 & 0.8 & \\
\hline I.5 & $70 \%$ & $30 \%$ & 0.47 & 458 & 0.8 & \\
\hline I.6 & $50 \%$ & $50 \%$ & 0.45 & 458 & 0.8 & \\
\hline I.7 & $25 \%$ & $75 \%$ & 0.45 & 458 & 0.8 & \\
\hline I. 8 & $0 \%$ & $100 \%$ & 0.45 & 459 & 0.8 & \\
\hline
\end{tabular}




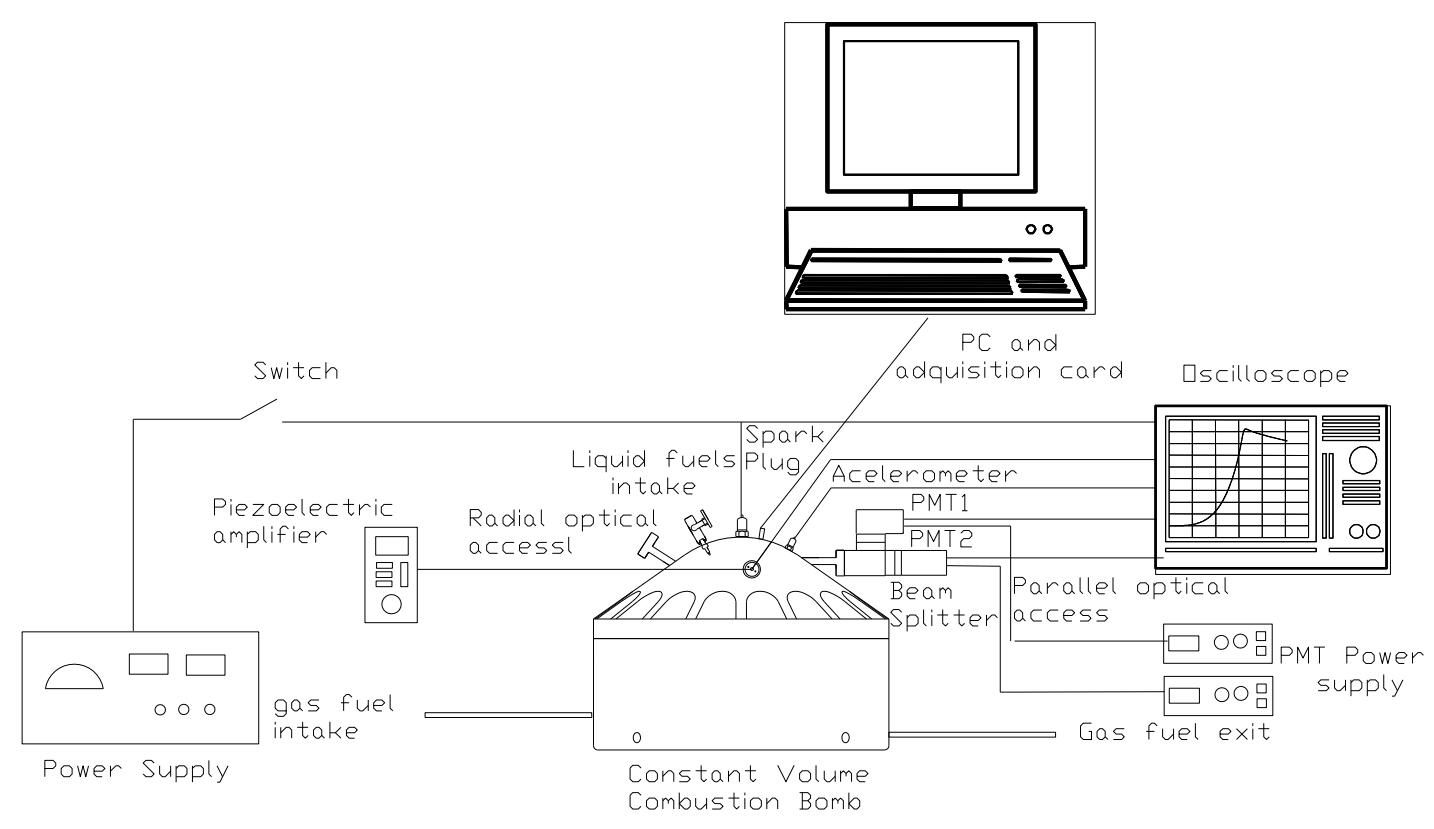

(i) Schematics of the experimental setup

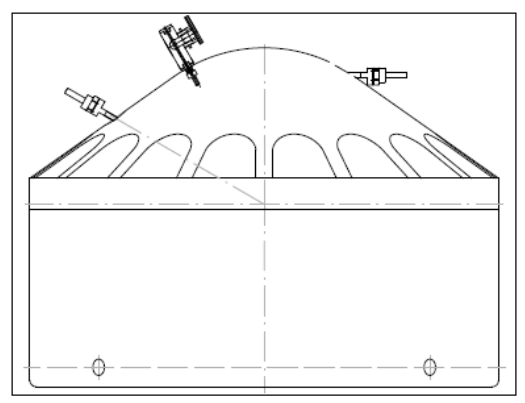

(ii) Layout of the orifices for the optical accesses

Figure 1. Sketch of the experimental facility 
Figure 2

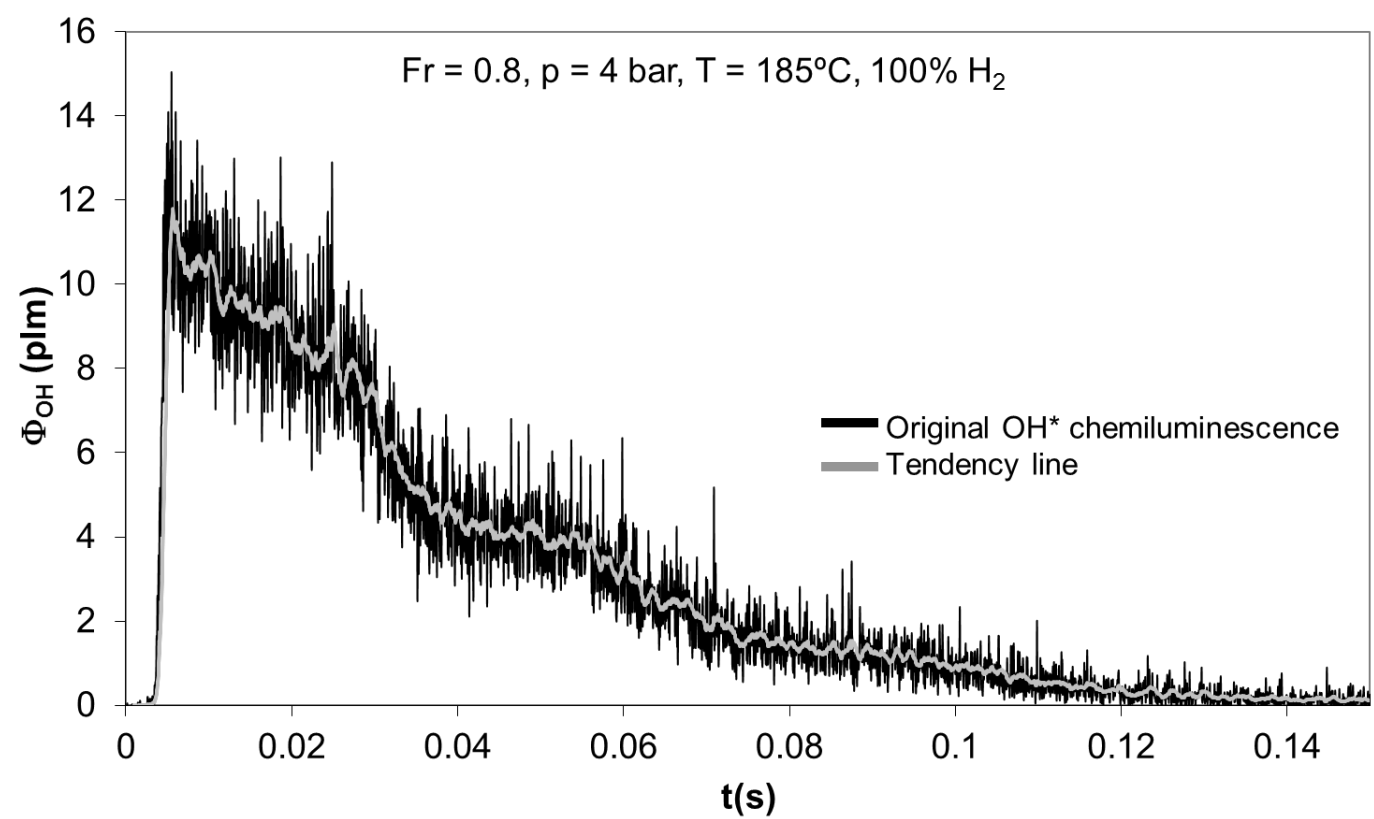

Figure 2. Original and smoothed curves of $\mathrm{OH}^{*}$ chemiluminescence 


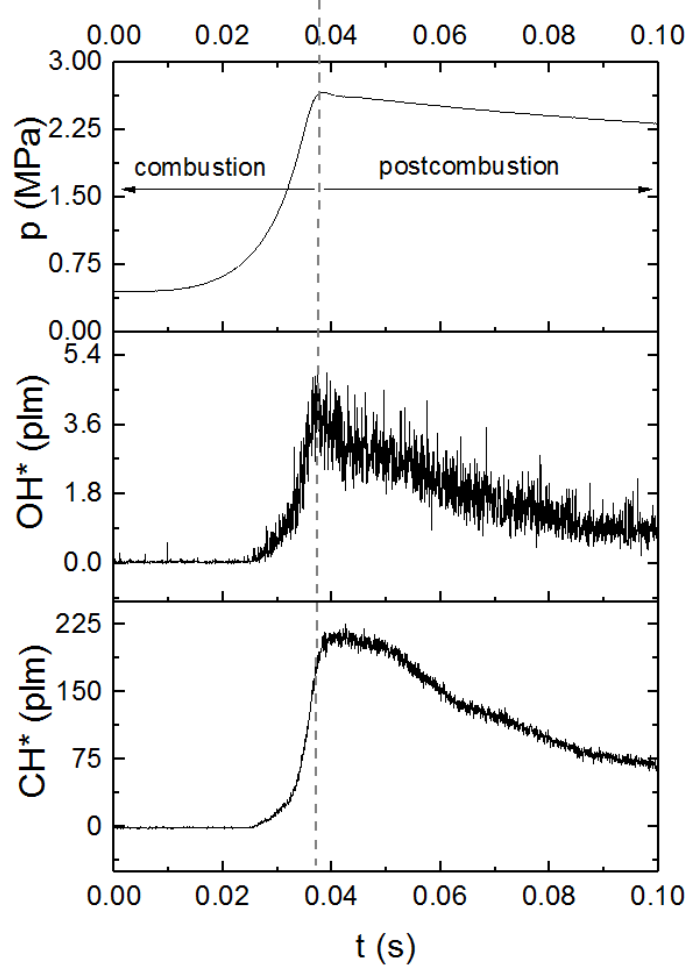

Figure 3. Example of time evolutions of pressure, $\mathrm{OH}^{*}$ and $\mathrm{CH}^{*}$ chemiluminescence emissions obtained from a combustion of 50\% natural gas and 50\% hydrogen blend, at initial conditions $0.45 \mathrm{MPa}, 458 \mathrm{~K}$ and 0.8 equivalence ratio 


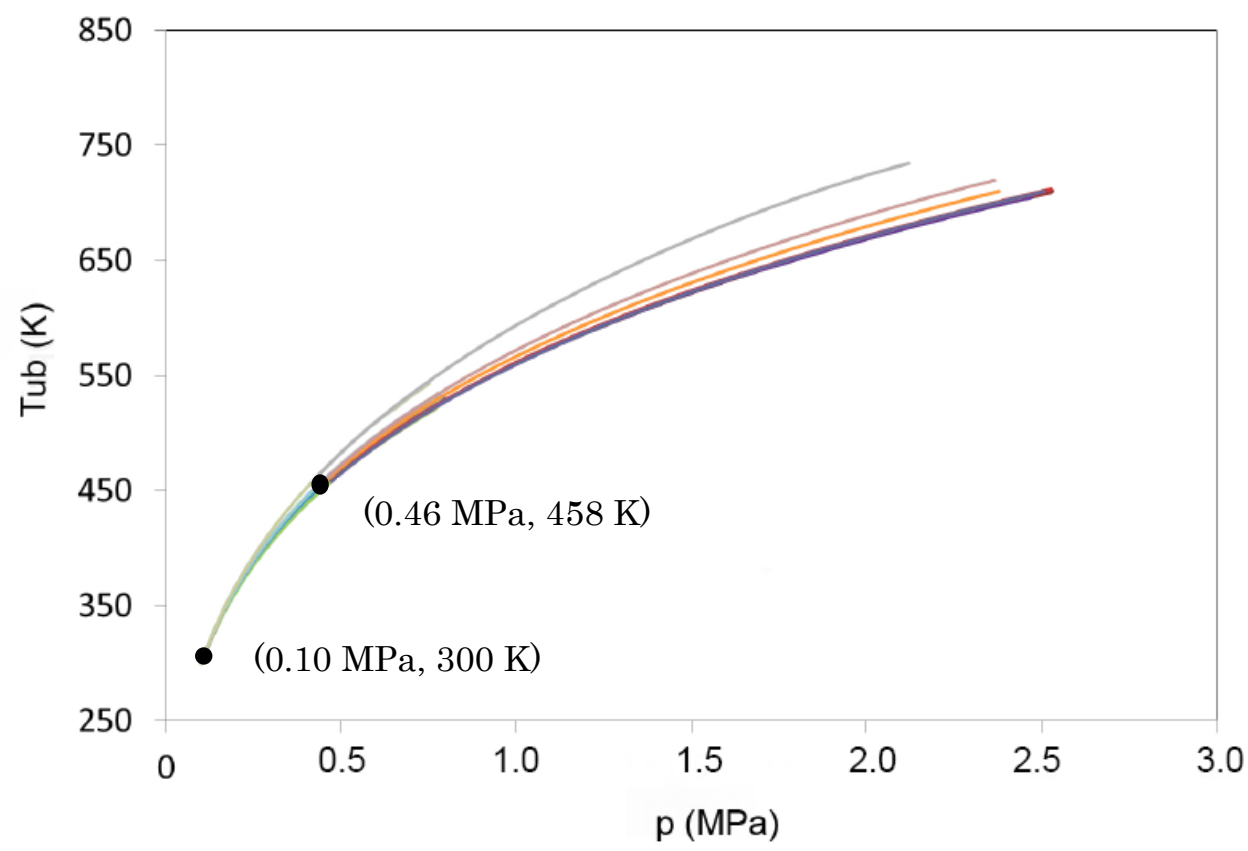

Figure 4. Temperature of unburned mixture versus chamber pressure for the experiments with hydrogen/methane mixtures. Colour lines identify individual experiments with the initial conditions of Table 1. 

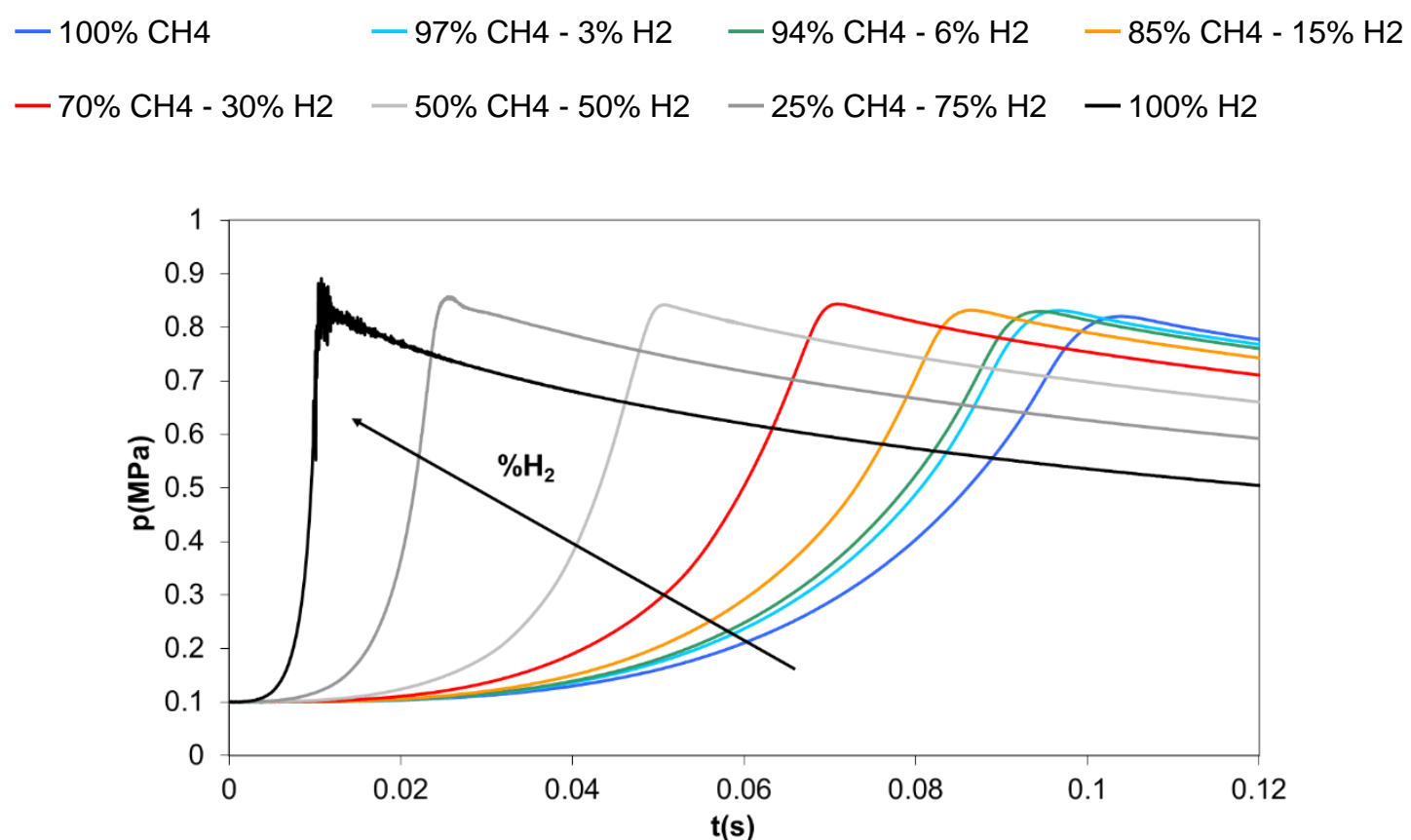

(i) Ambient initial conditions: $\mathrm{T}_{\mathrm{i}}=300 \mathrm{~K}$ and $\mathrm{p}_{\mathrm{i}}=0.1 \mathrm{MPa}$

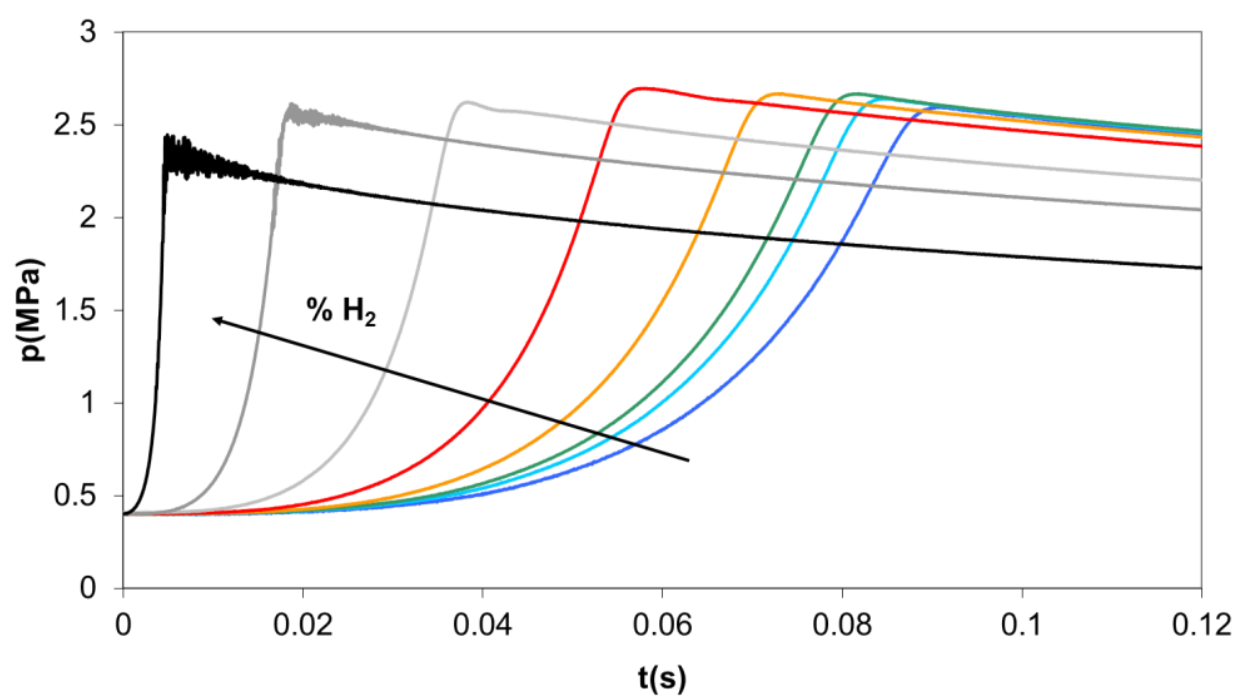

(ii) Intermediate initial conditions: $\mathrm{T}_{\mathrm{i}}=458 \mathrm{~K}$ and $\mathrm{p}_{\mathrm{i}}=0.46 \mathrm{MPa}$

Figure 5. Pressure evolution during the combustion of hydrogen/methane blends at the initial conditions of Table 1. 

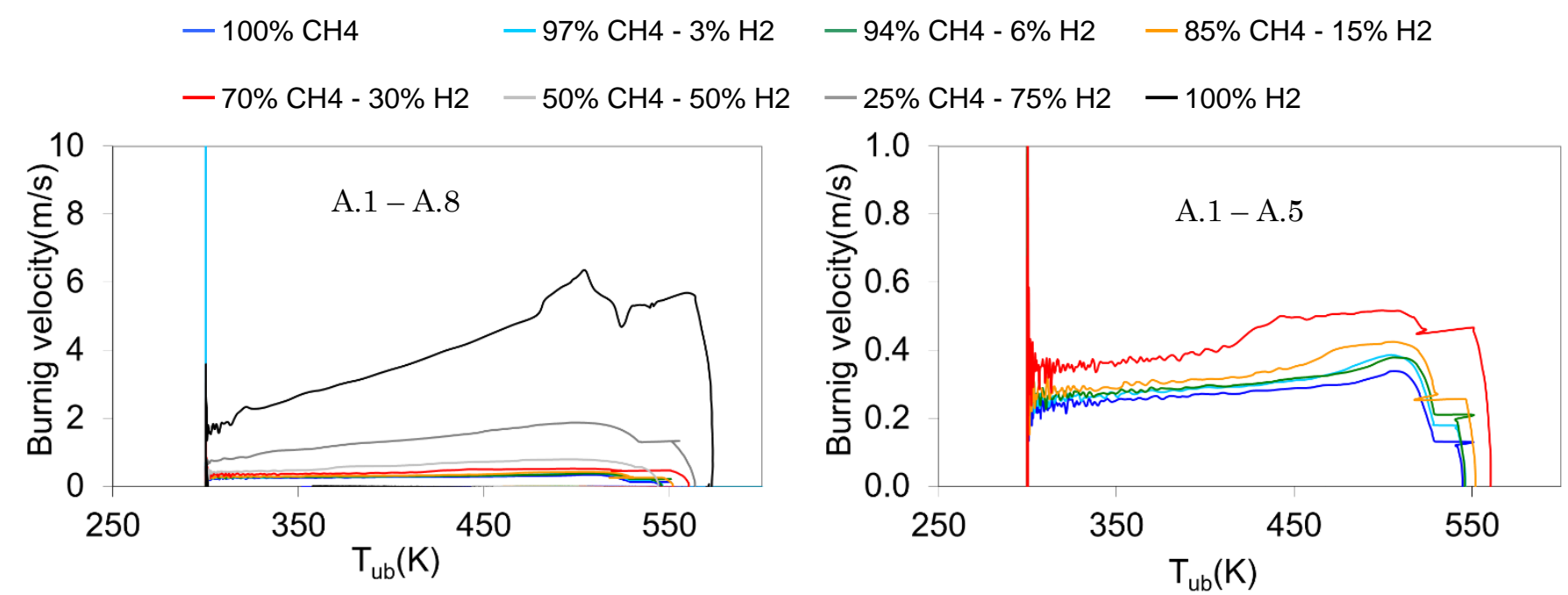

(i) Ambient initial conditions: $\mathrm{T}_{\mathrm{i}}=300 \mathrm{~K}$ and $\mathrm{p}_{\mathrm{i}}=0.1 \mathrm{MPa}$ (A.1 to A.8)
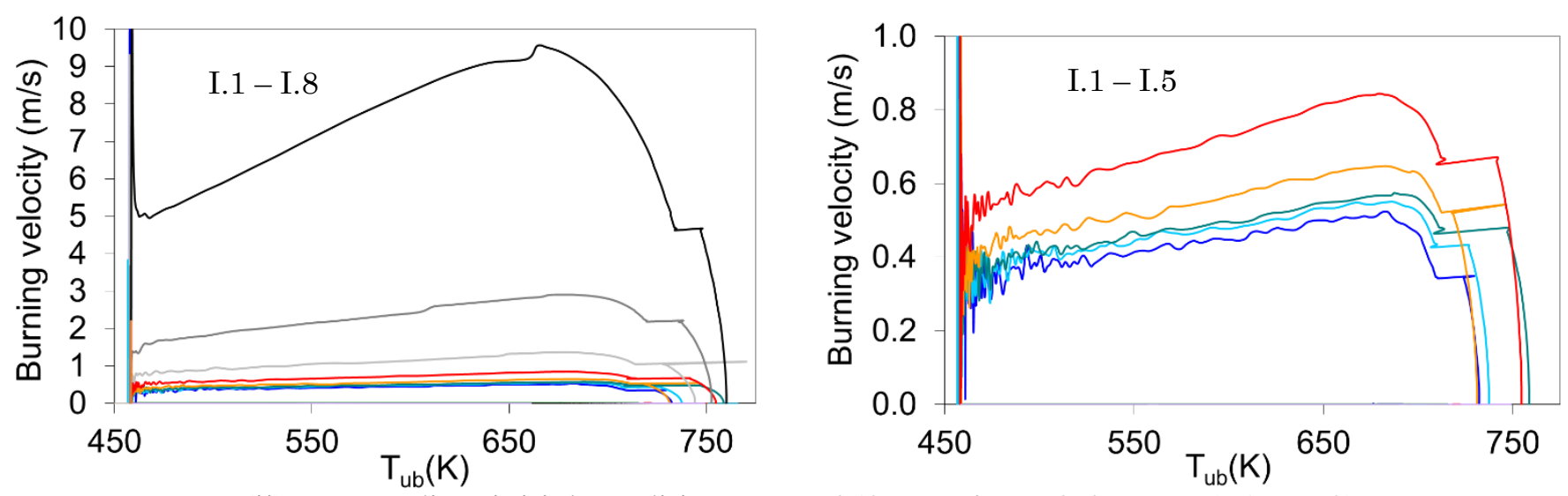

(ii) Intermediate initial conditions: $\mathrm{T}_{\mathrm{i}}=458 \mathrm{~K}$ and $\mathrm{p}_{\mathrm{i}}=0.46 \mathrm{MPa}$ (I.1 to I.8)

Fig 6. Burning velocity versus the unburned temperature during combustion of hydrogen/methane blends at the initial conditions of Table 1. 


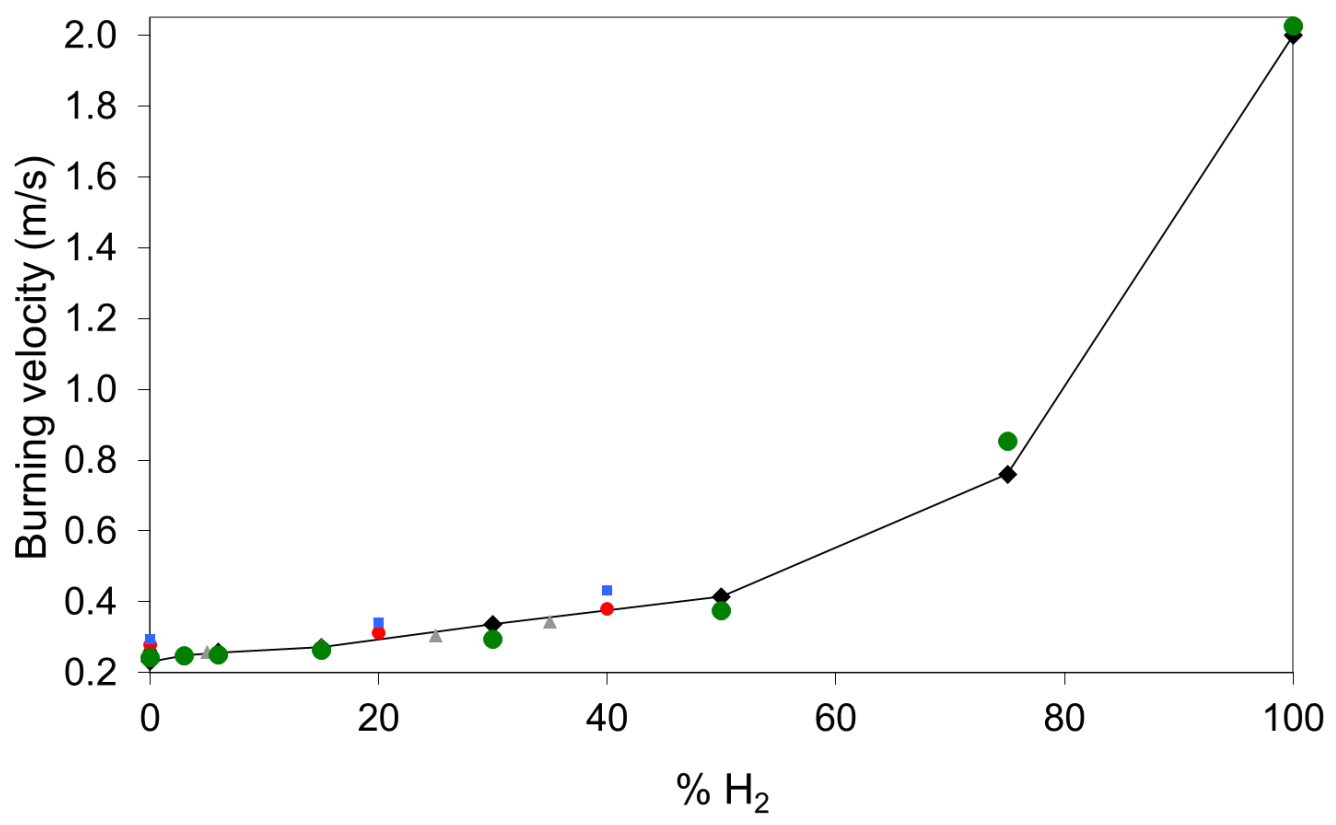

$\triangle$ Coppens et al. [46], ${ }^{\bullet}$ Huang et al. [5], $\square$ Tanoue et al. [47]

$\diamond$ Present work, $\quad$ Bougrine et al. [46]

Figure 7. Burning velocity of hydrogen/methane blends for a fuel/air equivalence ratio of 0.8 at $0.1 \mathrm{MPa}$ and $300 \mathrm{~K}$. 

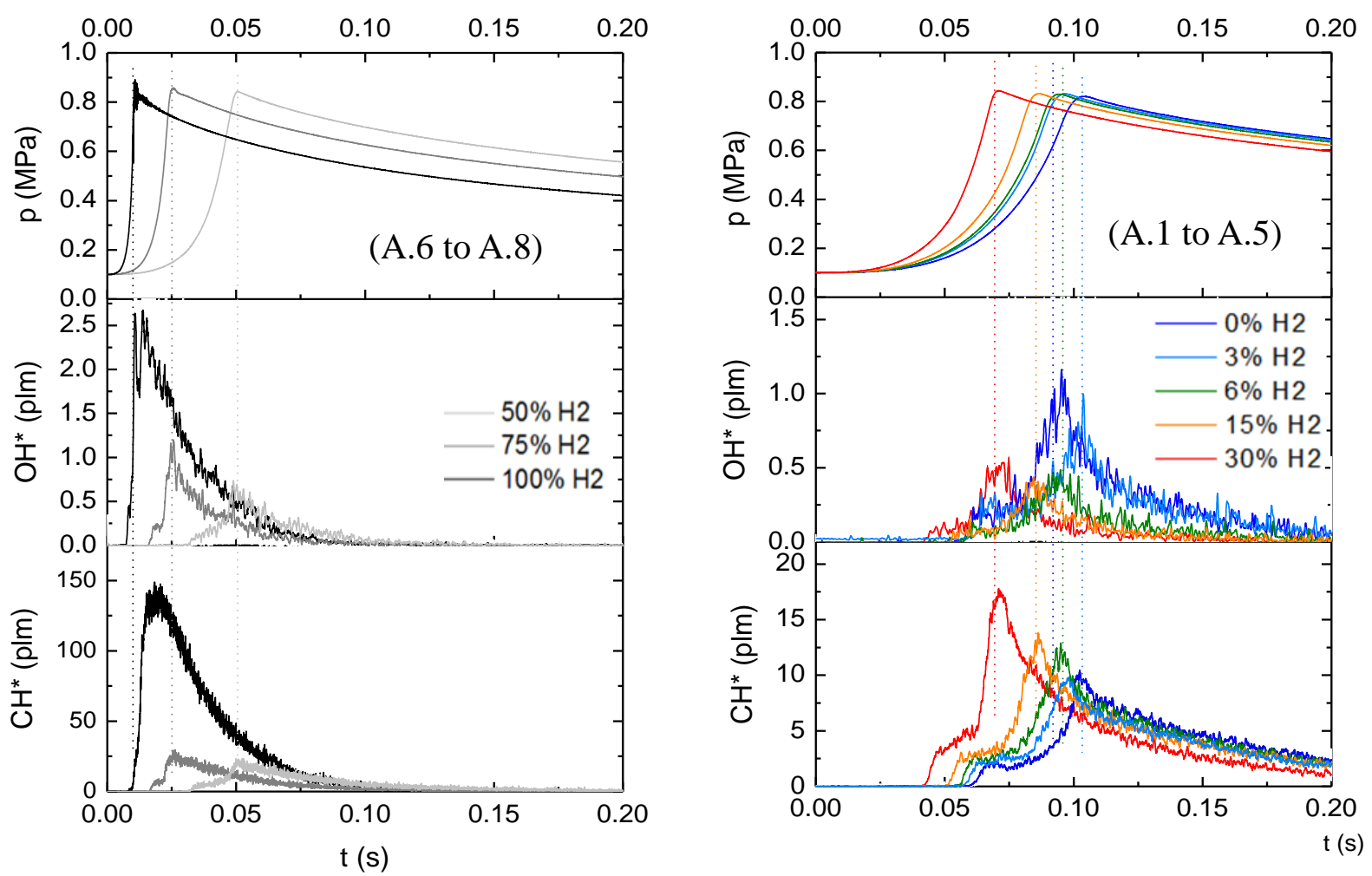

(i) Ambient initial conditions: $\mathrm{T}_{\mathrm{i}}=300 \mathrm{~K}$ and $\mathrm{p}_{\mathrm{i}}=0.1 \mathrm{MPa}$
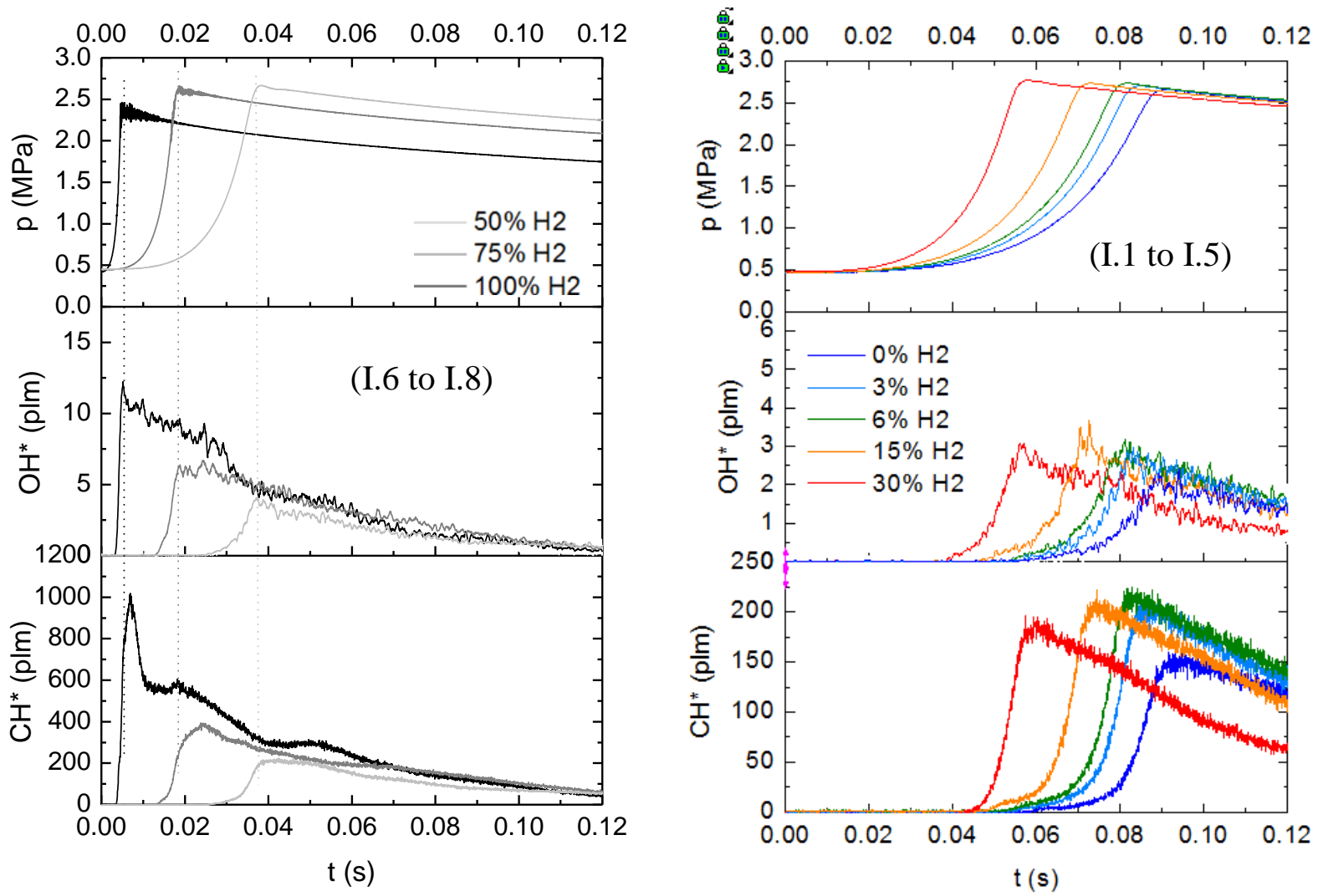
(ii) Intermediate initial conditions: $\mathrm{T}_{\mathrm{i}}=458 \mathrm{~K}$ and $\mathrm{p}_{\mathrm{i}}=0.46 \mathrm{MPa}$

Figure 8. Pressure, $\mathrm{OH}^{*}$ and $\mathrm{CH}^{*}$ chemiluminescence emissions during the combustion of hydrogen/methane blends (vertical dotted lines denote te end of combustion processes). 


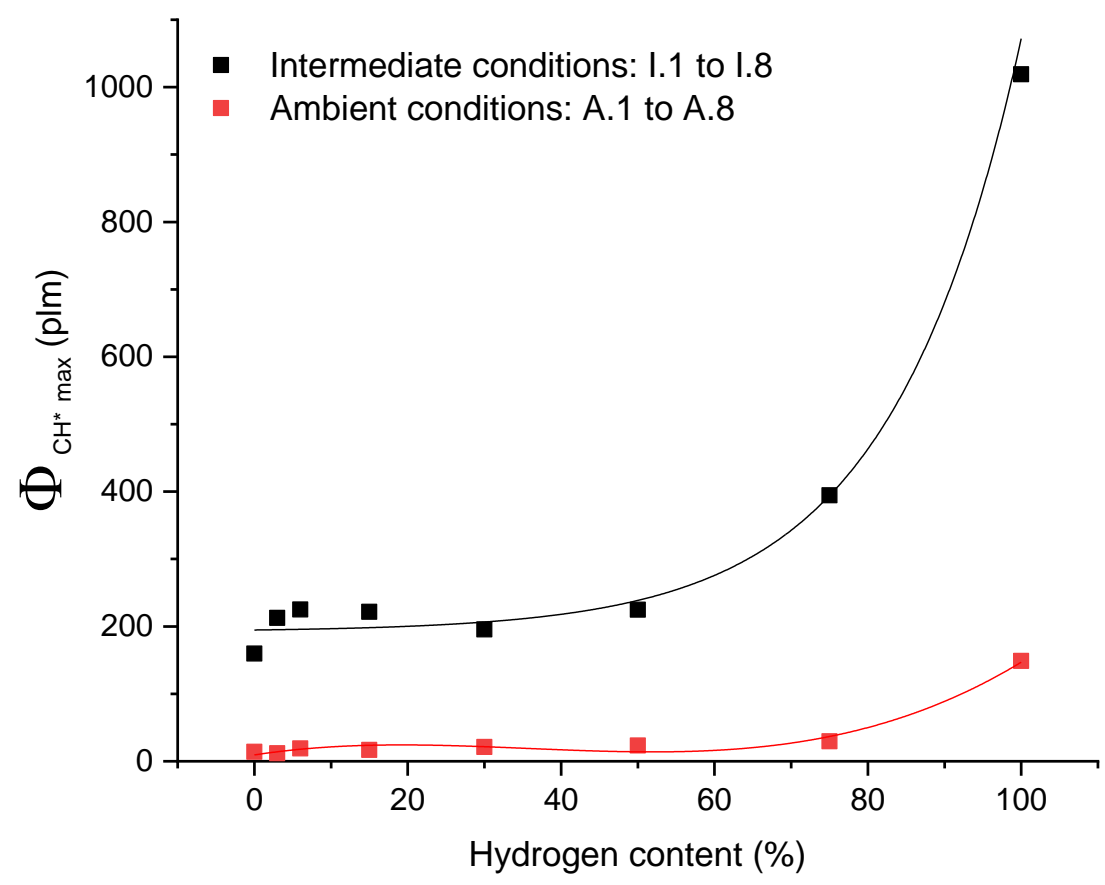

Fig 9. Maximum intensity of $\mathrm{CH}^{*}$ chemiluminescence emission versus the percentage of hydrogen in the fuel mixture in combustions of hydrogen/methane blends with the initial conditions presented in Table 1. 


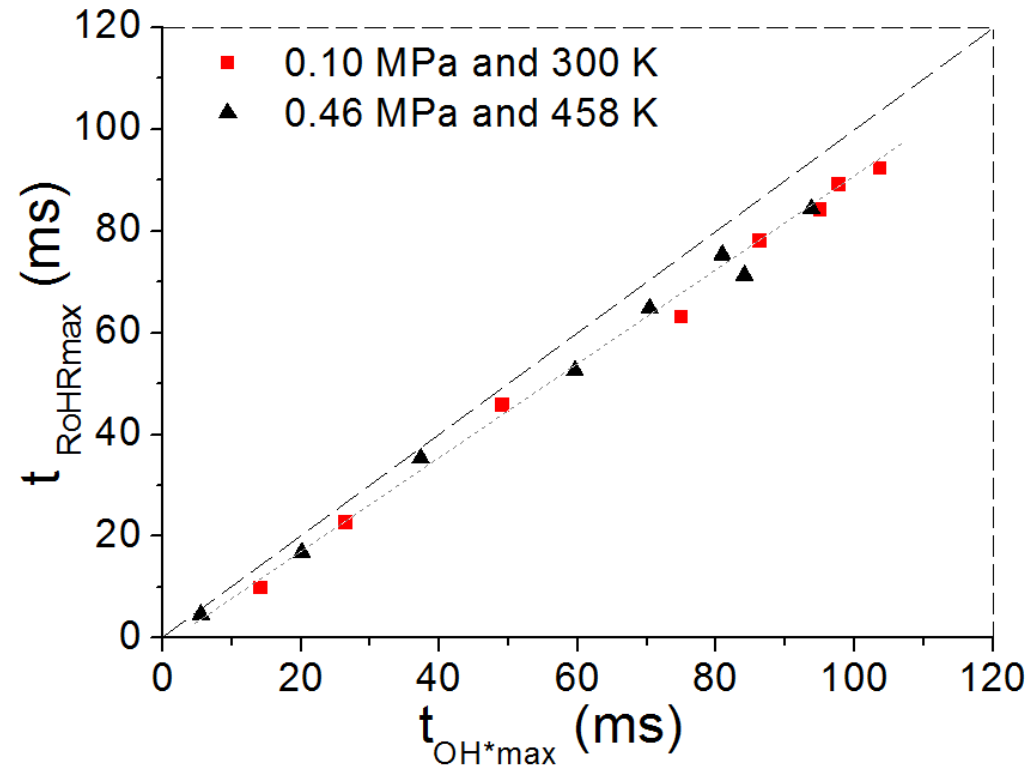

Figure 10. Time of $\mathrm{RoHR}_{\max }$ versus time of maxima $\mathrm{OH}^{*}$ chemiluminescence in combustions of hydrogen/methane blends with different proportions of both fuels, for a given fuel/air equivalence ratio of 0.8 (all experimental conditions) 


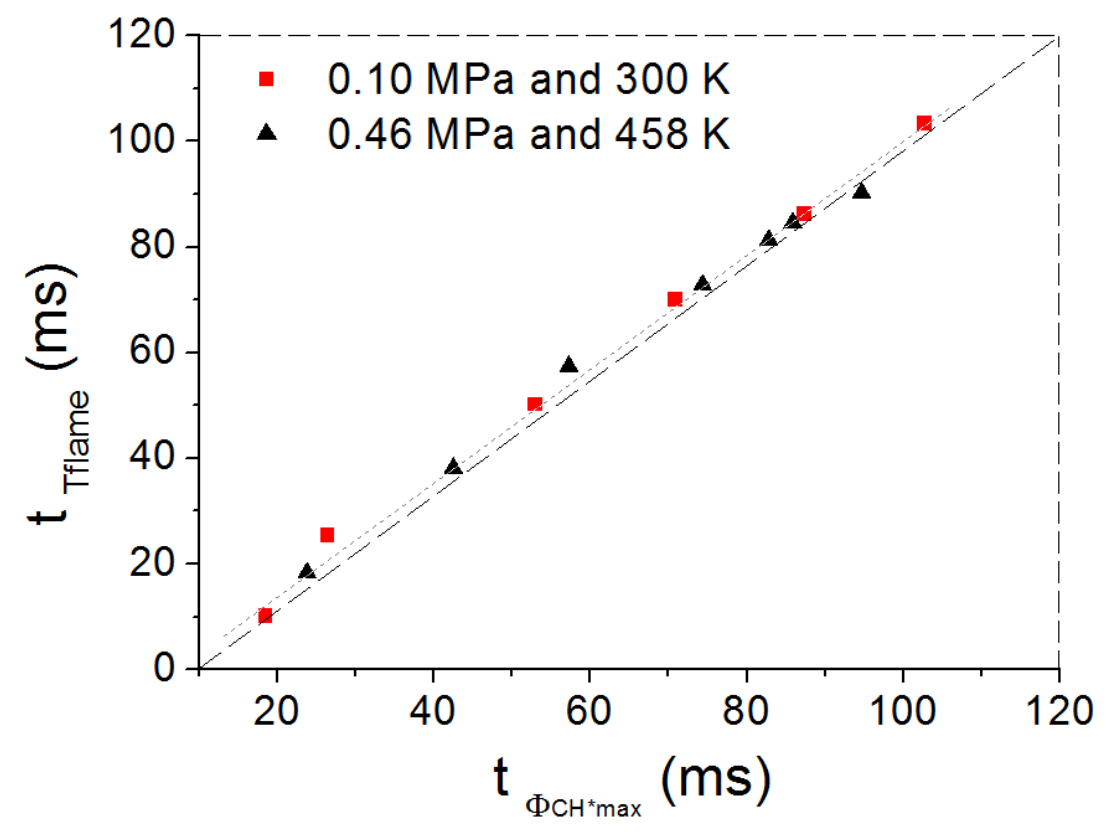

Figure 11. Flame temperature time vs. the maximum $\mathrm{CH}^{*}$ chemiluminescence emission time for combustions of hydrogen and methane blends in different proportions, for a fuel/air equivalence ratio of 0.8 (all experimental conditions) 